with a single chest radiograph. ${ }^{23}$ Bile acid malabsorption is a more common cause of important morbidity than is generally appreciated. It can be diagnosed easily and reliably by measuring the whole body retention of SeHCAT. Preliminary results in northern Sweden, where the diet has a higher fibre content than in Scotland, suggest that normal subjects there may retain less than $15 \%$ at seven days (Nyhlin, personal communication). The actual retention values are thus likely to vary in different populations and should be determined for each centre. We recommend that retention of SeHCAT should be measured routinely in patients with troublesome chronic diarrhoea for which no cause has been found.

We thank Amersham International for supplies of SeHCAT; Mrs S Kent for technical help; and our colleagues, especially Dr W Sircus and Dr A Ferguson, for allowing us to study patients under their care.

\section{References}

1 Dowling RH. Bile acids in constipation and diarrhoea. In: Barbara L, Dowling $\mathrm{RH}$, Hofmann AF, Roda $\mathrm{E}$, eds. Bile acids in gastroenterology. Boston: MTP Press, 1982:157-71.

2 Playoust MR, Isselbacher KJ. Studies on the transport and metabolism of conjugated bile salts by intestinal mucosa. $\mathcal{F}$ Clin Invest $1974 ; 43: 467-71$.

amuel P, Saupol GM, Meilman E, Mosbach EH, Chafidazeh M. Absorption of bile acids from the large bowel in man. $\mathcal{F}$ Clin Invest $1968 ; 47: 2070-3$.

Mekhiian HS, Philips SF, Hofmann AF. Colonic absorption of unconjugated

bile acids. Perfusion studies in man. Dig Dis $S c i$ 1976; 24:545-50.
van Blankenstein M, Hoyset T, Horchner P, Frenkel M, Wilson JHP. Faecal bile radioactivity, a sensitive and relatively simple test for ileal dysfunction. Neth $\mathcal{F}$ Med $1977 ; 20: 248-52$.
6 Ludgate SM, Merrick MV. The pathogenesis of post-irradiation chronic diarrhoea: measurement of SeHCAT and B12 absorption for differential diagnosis determines treatment. Clin Radiol (in press).

7 Thaysen EH, Pedersen L. Idiopathic bile acid catharsis. Gut 1976;17:965-70.

8 Fromm HD, Farivar H, McJunkin B. Type 3 bile acid malabsorption and diarrhoea. Evidence for a new clinical entity. Gastroenterology 1977;72:1060A

9 Barbara L. Bile acid malabsorption. In: Barbara L, Dowling RH, Hofmann AF Roda E, eds. Bile acids in gastroenterology. Boston: MTP Press, 1982:172-82.

10 Boyd GS, Merrick MV, Monks R, Thomas IL. Se-75-labelled bile acid analogues new radiopharmaceuticals for investigating the enterohepatic circulation. f Nucl Med 1981;21:720-5.

1 Merrick MV, Eastwood MA, Anderson JA, Ross HMcL. Enterohepatic circulation in man of a gamma emitting bile acid conjugate, 23-selena-25-homotauro-

WG. Evaluation of ileal function using 23-selena-25-homotaurocholate, a gamma-labelled conjugated bile acid. using 23-selena-25-homotauroch

$13 \mathrm{Cohn} \mathrm{SH}$, Palmer HE. Advances in whole-body counting: a review. Int $\mathcal{f} \mathrm{Nucl}$ Med Biol 1974:1:155-65.

14 Delhez H, van den Berg JWO, van Blankenstein M, Meerwaldt JH. A new method for the determination of bile acid turnover using $75 \mathrm{Se}$-homocholic acid taurine. Eur F Nucl Med 1982;7:269-71.

15 Metz G, Gassull MA, Drasar BS, Jenkins DJA, Blendis LM. Breath hydrogen test for small intestinal bacterial colonisation. Lancet 1976 ; : $: 668-9$.

16 Heaton KW. Bile salt tests in clinical practice. Br Med f 1979;1:644-6. Thaysen EH, Orholm M, Arnfred T, Carl J, Rodbro P. Assessment of ilea function by abdominal counting of the retention of a gamma emitting bile acid analogue. Gut $1982 ; 23: 862-5$.

18 Fagan EA, Chadwick VS, Baird IMcL. SeHCAT absorption: a simple test of ileal dysfunction. Digestion $1982 ; 26: 159-65$.

19 Fromm H, Thomas PJ, Hofmann AF. Sensitivity and specificity of tests of distal ileal function: prospective comparison of bile acid and vitamin B12 absorption 1973.64:1077-90.

作 Br f Surg 1983;70:177-9.

21 Hames TK, Condon BR, Flemming JS, et al. A comparison between the use of a shadow shield whole-body counter and an uncollimated gamma camera in the assessment of the seven-day retention of SeHCAT. Br F Radiol 1984;57:581-4. 22 Hinton PJ, Taylor DN, Wyke RJ, McIntosh JA. Application of different counting systems in measuring localised retention in the enterohepatic circulation. Br F Radiol 1984;57:799-802.

23 Soundy RG, Simpson JD, Ross HMcL, Merrick MV. Absorbed dose to man from the Se-57 labelled conjugated bile salt SeHCAT. F Nucl Med 1982;23
$157-61$.

(Accepted 19 December 1984)

\title{
Older women's attitudes towards breast disease, self examination, and screening facilities: implications for communication
}

\author{
D S LEATHAR, M M ROBERTS
}

\begin{abstract}
Qualitative research techniques were used in two studies in Edinburgh to explore older women's attitudes and motivations towards breast disease, self examination, and screening, with a view to identifying appropriate strategies for communication. The results indicated that knowledge of breast disease and screening facilities was poor and that many psychological and emotional issues inhibited self examination.

Increasing information about self examination and clinics is unlikely to influence uptake unless it is presented together with emotional support rather than through
\end{abstract}

Advertising Research Unit, University of Strathclyde D S LEATHAR, PHD, director

\footnotetext{
Edinburgh Breast Screening Clinic and Department of Clinical Surgery, University of Edinburgh, Edinburgh

M M ROBERTS, MD, clinical director and senior lecturer

Correspondence to: Dr M M Roberts, Breast Screening Clinic, Springwell House, Edinburgh EH11 2JL.
}

conventional mass media channels. Such support may best be provided by setting breast screening within general health screening rather than emphasising the single disease.

\section{Introduction}

Several studies have suggested that those women who do not take up opportunities for screening may be older and poorer than those who attend clinics offering screening services. ${ }^{1-3}$ The same may be true for acceptance of self examination of the breasts, but uptake of screening or the practice of self examination seems likely also to depend on a woman's underlying motivations and attitudes towards breast disease. Most studies on these aspects have been carried out in women who already have some problem with their breasts. ${ }^{45}$ We therefore thought that the relation between women's motivations and attitudes to breast disease, self examination, and screening facilities required further study, especially in relation to social class.

In exploring women's attitudes to topics as sensitive as breast cancer we thought that a qualitative research approach using group discussions might be most useful. ${ }^{6}$ The technique derives from market research, doctors being either unfamiliar with it or sceptical about its relevance in medicine. It is now, however, well established in health education research, especially in Scotland, 
and has provided the methodology for basic research into the reasons underlying attendance and non-attendance at other types of health related clinics. ${ }^{7}{ }^{8}$ Small groups of six to eight people with specified sociodemographic characteristics are recruited through quota sampling and asked to discuss a topic under the direction of a psychologist. Aspects are explored and discussed rather than specific questions asked, and the opportunity for interaction allows topics to be explored in greater depth than conventional questionnaire techniques sometimes permit. Provided all intended aspects are covered by the end of the discussion, respondents specify their own priorities in discussing the topic, using their own language to do so. The method therefore avoids one of the common failings of questionnaire research, which is exploring only those issues judged to be important by the researcher and thus reflecting his biases and preconceptions. Furthermore, the opportunity for interaction allows the researcher to use complicated interviewing techniques, especially projective methods, many of which have been developed by market researchers. These are particularly useful in exploring complex issues such as imagery and motivation.

We report here the results of two studies. The first, in 1980, was exploratory, providing information on attitudes and motivation about breast disease, self examination, and screening with particular emphasis on the implications for communication strategy in a health education programme being planned for Edinburgh. ${ }^{9}$ Subsequently, another study was done, in 1982, to explore the relation of attitudes and motivation to social class, especially in relation to attendance at the Edinburgh Breast Screening Clinic by older women. The current trial of screening for breast cancer has been described elsewhere, but by 1982 we already knew that only two thirds of women in the age group 45-65 took up the offer of screening. ${ }^{10}$

\section{Subjects and methods}

Altogether 18 group discussions were carried out, 15 with women and three with men, giving a total sample size of 136 (table). Respon-

Sample structure

\begin{tabular}{rrrrr}
\hline Group & Age range (years) & Socioeconomic state* & Sex & No of participants \\
\hline & & First study $(1980)$ & & \\
1 & $40-60$ & ABC1 & F & 8 \\
2 & $40-60$ & BC1C2 & F & 8 \\
3 & $40-60$ & C2DE & F & 8 \\
4 & $30-45$ & ABC1 & F & 8 \\
5 & $30-45$ & BC1C2 & M & 8 \\
6 & $35-65$ & Second study $(1982)$ & & \\
& & C1C2D & F & 7 \\
1 & $45-65$ & C1C2D & F & 7 \\
2 & $45-65$ & C1C2D & F & 8 \\
3 & $45-65$ & C1C2D & F & 8 \\
4 & $45-65$ & D $2 D$ & F & 8 \\
5 & $45-65$ & ABC1 & F & 7 \\
6 & $45-65$ & ABC1 & F & 8 \\
7 & $45-65$ & C1C2D & F & 7 \\
8 & $45-65$ & C1C2D & M & 8 \\
9 & $45-65$ & C1C2D & M & 7 \\
10 & $20-45$ & $45-65$ & & \\
11 & $45-65$ & & & 7 \\
12 & & &
\end{tabular}

*Definitions according to standard market research criteria. ${ }^{14}$

dents were recruited by professional market research interviewers and asked to attend the discussions, which were held in a private house. Considerable care was taken to ensure that those attending would not be distressed by the topic, and anyone with recent illness, especially breast disease either of themselves or in their family, was excluded. Respondents were not told the precise subject to be discussed, which was described as being about "attitudes towards health care including serious diseases."

The principal aspects covered were knowledge of and attitudes towards breast disease, attitudes towards breast self examination and screening, reasons for uptake or lack of uptake of early diagnostic facilities, and communication issues. Eight of the groups were led by a woman interviewer and seven by a man. The respondents were paid a standard fee for participation, and each group discussion lasted for about one and a half hours.

\section{Results}

\section{KNOWLEDGE OF BREAST DISEASE}

Knowledge of the symptoms and extent of breast disease was poor. Breast disease was equated with having a lump that was either benign (removable and curable) or malignant (ultimately fatal), a distinction impossible for women themselves to determine as expert knowledge was required.

Confusion was also shown about the signs and symptoms of breast cancer-for example, about the relation to pain and the meaning of skin puckering and nipple inversion. The causes were thought not to be different from those of cancer in general, which was most often attributed to general environmental factors. Almost all women believed that cancer spreads inevitably to other parts of the body. Specific beliefs about breast cancer's association with breast feeding or the pill were very undeveloped, being merely restatements of the more emotional media publicity.

There was only superficial awareness that women aged over 40 were more at risk, although older people were accepted as being more susceptible to cancer in general. In terms of prognosis, a pessimistic view of cancer's terminal nature, other than when "caught early enough," tended to dominate. There was, however, considerable debate about what being caught early enough actually meant in practice: whether it was defined by the size of the lump; implied any pain; or was cancer identified by machinery but not far enough advanced to be identified by examination. Although there was a vague acceptance that most lumps were benign, the immediate conclusion of virtually all women interviewed was that any lump they found themselves was bound to be malignant.

Surgery was the only method of treatment mentioned to any extent. Benign lumps were removed, whereas malignant lumps resulted in mastectomy. Partial versus complete mastectomy was virtually unknown as was the possibility of women having a choice in the treatment given. Also, mastectomy was not necessarily equated with guaranteeing recovery. It was simply seen as the removal of a cancer, which, depending on how advanced it was, might or might not lead to eventual cure. There was no awareness at all of the cure rate within a five year period.

\section{ATTITUDES TOWARDS BREAST CANCER}

Breast cancer was a highly emotive, deeply threatening topic. For younger respondents most fears related to the psychological implications of being incomplete in the feminine sense, such as changes in self concept, relations with husbands and children, and coping with a world in which losing a breast is still regarded as abnormal. There were also fears of being visibly abnormal; despite the quality of modern prostheses there was the overwhelming belief that people would know and would be constantly looking at them.

Older women stated that they would feel under less psychological pressure of this type. While there was still the fear of being incomplete, they thought they would be under less pressure from friends and relatives "examining" them. They also claimed greater emotional support from their husbands, as their marriages would be longer lasting with less emphasis on sexual relations. Instead, their pressures were more generalised, resulting more from the fear that their susceptibility to cancer in general had been confirmed and was constantly visible.

\section{ATTITUDES TOWARDS SELF EXAMINATION}

Older women found self examination difficult to carry out on any regular basis for three reasons. Firstly, they found difficulties in accepting the psychological "niceness" of examining this part of the body; this was primarily due to attitudes to sex in their younger days, when it was a culturally repressed subject. Secondly, although many women accepted on a logical level that self examination should be carried out to find any abnormalities, in practice it was often done to find nothing wrong and to reinforce this belief. As a result it was carried out unsystematically, irregularly, and superficially, with indifference to educational programmes encouraging it and, to some extent, reluctance to learn the correct procedure. Finally, there was uncertainty in knowing what to look for other than a lump. There were 
also uncertainties about normal variations, the frequency and timing of the examination, and the techniques to use.

\section{KNOWLEDGE OF AND ATTITUDES TOWARDS BREAST SCREENING}

Women were confused about what services were available, though most knew of at least some form of screening facility. Knowledge was poor of both the breast screening clinic and well woman clinics, especially in terms of the services offered, patient age group, the range of tests that took place, the need for referral, and their relation to other clinics. They were, however, judged to be a service that should be encouraged and expanded, and, indeed, there was uncertainty about why they were not more widely known.

Two basic reasons were given for attending regularly. Firstly, the logical rational consideration that early diagnosis minimised the consequences of serious illness. This required a long term perspective. Secondly, to obtain psychological reassurance to a deep seated worry. This type of behaviour was particularly associated with women who described themselves as worriers and had a strong need for reassurance in situations that caused anxiety. This had to be resolved on some objective basis, the most obvious one being to attend a clinic for a professional verdict of "all clear."

Many reasons emerged for not attending clinics. Although it was recognised on an intellectual level that breast disease would have a profound effect on their family responsibilities, many women claimed that day to day considerations prevented this from being translated into action. Preventive behaviour such as attending clinics also appeared to offer nothing positive in any tangible sense but only the negative possibility of finding something wrong.

Some women did not consider the service important enough to warrant their attention. A related issue was that many, while regarding the service as relevant, did not see it as important enough to justify action. This did not imply that they had any particular fears about it, merely that they needed a stimulus to turn good intentions into actual behaviour.

Embarrassment at attending clinics for physical examination was also mentioned. This included having to relate to professional staff and being with strangers in a potentially emotional situation (such as coping with distress if something is found). Some women were anxious about the clinic procedure. Others were concerned that they were making a nuisance of themselves in wasting valuable professional time. It was also commented that "clinics" were not for healthy people. "Centre" was suggested as a term with fewer emotionally negative connotations.

Finally, most older women accepted that breast screening was a "good thing" that should be encouraged by society as a whole and by government and the National Health Service. These beliefs, however, were almost always thought to be applicable to other people but not to the subject herself.

\section{Discussion}

Some of our findings will be familiar to most doctors, but possibly little attention is paid to them. One example is women's lack of knowledge of signs and symptoms other than the presence of a lump. This finding was confirmed in another, quantitative study of women's knowledge. ${ }^{11}$ Other studies have shown that delay in seeking advice is related to this lack of knowledge. ${ }^{12}$

The widespread knowledge of the secondary spread of cancer is one that we should note as doctors' difficulties in describing metastatic disease to patients are irrational in view of this. Appropriate reassurance about the absence of spread is equally important for patients. Despite many newspaper articles and television programmes most women know little about new treatments of breast cancer, and clinicians should remember this. The confusion and lack of knowledge about existing screening facilities and well woman clinics show a lack of positive communication from health professionals, which could be improved by appropriate means.

An interesting finding was the tendency of many women to carry out breast self examination in a way that ensured that no abnormality was found. This highlights the difficulties in teaching women this technique. Although factual knowledge can be improved, the desire not to find anything wrong will be less easy to deal with. In fact, because of this many women were somewhat pessimistic about the likely success of teaching self examination and argued that unless it is established as a positive habit early on in life it would be extremely difficult to break the counter habit of non-examination.

The study also has important implications for breast screening among older, working class women. Merely reminding them of the logical advantages is fraught with problems. Great care should be taken in making the assumption that simply providing increased factual information will encourage early diagnosis; the reasons for not using screening facilities were largely unrelated to factual knowledge. The prime reason was emotionally based, to do with coming to terms with the developing expectation of ill health rather than the absence of specific information, although factual information was in no way complete or accurate. Anything that highlights the possibility of ill health or the individual's vulnerability, such as the request to attend a screening clinic, may therefore be dismissed, even though the case for attending is accepted and even encouraged at an intellectual level.

To succeed in overcoming these emotional fears that lie at the core of non-attendance would require procedures that breast screening is perhaps not capable of providing on its own. In particular, it would have to provide some general psychological reassurance allowing older women to cope with the diffuse threat of ill health or provide a clean bill of health from all potentially serious threats of ill health. These requirements are more in line with breast screening being set within a wider context of general health screening rather than emphasising a single disease. The policy that breast screening should be offered as a single exercise may therefore be quite inappropriate for older women, particularly in some social groups. This implication is important but requires further work before any policy could be suggested. It is interesting that women who do not respond to an invitation for screening tend to be older and are more likely to be working class than women who accept. ${ }^{313}$

In conclusion, the implications for communication are relatively clear. There are many areas of factual uncertainty about breast disease and self examination. Normally this would imply some mass educational approach. Because emotional support is required as well, however, it is more likely to be achieved through personal, face to face communication such as counselling, when information can be presented together with emotional support, than through mass media channels such as television. It is our view that using mass media channels alone could only increase anxiety, which achieves nothing unless the means to resolve it are also provided.

\section{References}

1 Smith A. Preserving the future-the potential of population screening. Health and Hygiene 1978;1:147-51.

Macgregor JE, Baird D. Detection of cervical carcinoma in the general population. Br Med f 1963; ; :1631-6.

3 French K, Porter AMD, Robinson SE, McCallum F, Howie JGR, Roberts MM. Attendance at a breast screening clinic: a problem of administration or atti982;285:617-20.

4 Magarey CJ, Todd PB, Blizzard PJ. Psychological factors influencing delay and breast self-examination in women with symptoms of breast cancer. Soc $S_{c i}$ Med 1977;11:229-32.

5 Green LW, Roberts BJ. The research literature on why women delay in seeking medical care for breast symptoms. Health Education Monographs 1974;2: 129-77.

6 Cooper P, Braithwaite A. Qualitative technology : new perspectives on measurement and meaning through qualitative research. In: Proceedings of Market Research Society 20th annual conference. Brighton: Market Research Society, 1977:79-92.

7 Bostock Y, Leathar DS. The role of the mass media in educating teenagers about contraception. British fournal of Family Planning 1982;8:59-63.

Blinkhorn AS, Hastings GB, Leathar DS. Attitudes towards dental care among young people: implications for dental health education. Br Dent $\mathcal{F}$ 1983;155: $311-4$.

Roberts MM, French K, Robinson SE. The
UICC Technical Reports 1984;77:39-48.

10 Roberts MM, Alexander FE, Anderson TJ, et al. The Edinburgh randomised trial of screening for breast cancer. Br $\mathcal{f}$ Cancer $1984 ; 50: 1-6$.

trial of screening for breast cancer. Br f Cancer $1984 ; 50: 1-6$. Roberts MM, French K, Duffy J. Breast cancer and breast s
what do Scottish women know ? Soc Sci Med 1984;18:791-7.

12 MacArthur C, Smith A. Delay in breast cancer and the nature of presenting symptoms. Lancet $1981 ; \mathrm{i}: 601-3$.

13 MacClean U, Sinfield D, Klein S, Hamden B. Women who decline breast screening. 7 Epidemiol Community Health $1984 ; 38: 278-83$.

14 Monk D. Social grading on the national readership survey. London: Research Services Ltd, Joint Industry Committee for National Readership Surveys (JIC-NAR), 1970.

(Accepted 5 December 1984) 